\title{
TECNOLOGIA DIGITAL DE INFORMAÇÃO E COMUNICAÇÃO COMO RECURSO PEDAGÓGICO NO ENSINO DA LÍNGUA PORTUGUESA
}

\author{
Rosana Maria Santos Torres Marcondes* \\ Anne Alilma Silva Souza Ferrete \\ Willian Lima Santos ${ }^{* * *}$
}

\begin{abstract}
RESUMO: O presente trabalho tem como objetivo apresentar práticas pedagógicas a partir do ensino híbrido na Educação Básica, na perspectiva da rotação por estações, destacando a importância do uso das Tecnologias Digitais de Informação e Comunicação (TDIC) e das metodologias ativas para a personalização do ensino de Língua Portuguesa. Metodologicamente, trata-se de pesquisa qualitativa, do tipo descritiva com uso de procedimentos empíricos. A pesquisa foi realizada com uma turma do $8^{\circ}$ ano de uma escola particular da cidade de Aracaju-SE/Brasil. Como resultados, identificou-se a possibilidade do professor, ao inovar a sua prática, aumentar o nível de interação e de motivação dos alunos no desenvolvimento das atividades de Língua Portuguesa, evidenciando a importância do uso do ensino híbrido e da tecnologia digital no processo ensino e aprendizagem.
\end{abstract}

PALAVRAS-CHAVE: Ensino Híbrido; Língua Portuguesa; Metodologias Ativas; Tecnologias digitais.

\section{Introdução}

Observa-se que está cada vez mais difícil motivar os alunos da Educação Básica com aulas expositivas e práticas pedagógicas em que o professor é o dono do saber e estabelece com o estudante uma relação unilateral. Virou clichê para o docente de Língua Portuguesa ouvir dos alunos, frases do tipo: “eu não preciso estudar Português, pois já sei falar e escrever" ou "Português é muito chato ou muito difícil", desse modo, escolheu-se analisar neste estudo, como o ensino híbrido ${ }^{1}$ integrado as Tecnologias Digitais de Informação e

\footnotetext{
* Mestranda em Educação pela Universidade Federal de Sergipe (UFS).

** Doutora em Educação pela Universidade Federal do Rio Grande do Norte (UFRN). Professora da Universidade Federal de Sergipe (UFS). Líder do Núcleo de Pesquisa em Comunicação e Tecnologia (NUCA/UFS). *** Mestrando em Educação pela Universidade Federal de Sergipe (UFS). Pesquisador vinculado ao Núcleo de Pesquisa em Comunicação e Tecnologia (NUCA/UFS).

${ }^{1}$ Modelo de educação formal que se caracteriza por mesclar dois modos de ensino: o online e o offline.
} 
Comunicação (TDIC), podem potencializar o ensino de Língua Portuguesa e estimular o aluno para o estudo da língua nativa.

Diante desse cenário desafiador, surge o problema: que caminho o professor precisa trilhar para inserir o ensino híbrido e a tecnologia digital nas práticas pedagógicas do ensino de Língua Portuguesa? Parte-se do pressuposto que, as aulas de Língua Portuguesa, dinamizadas pelas tecnologias digitais aliadas ao uso das metodologias ativas, podem oferecer ao professor possibilidades de novas abordagens pedagógicas que contribuam para o desenvolvimento do processo de ensino e aprendizagem significativa.

Este estudo tem como objetivo apresentar práticas pedagógicas, a partir do ensino híbrido na Educação Básica, na perspectiva da rotação por estações², destacando a importância do uso das TDIC e das metodologias ativas para a personalização do ensino de Língua Portuguesa, no $8^{\circ}$ ano do Ensino Fundamental de uma escola particular de Aracaju-SE. As aulas foram planejadas e desenvolvidas no mês de fevereiro de 2020 - importante ressaltar que a prática ocorreu na modalidade presencial, antes da suspensão das aulas devido a pandemia de Covid-19; integrando a tecnologia digital, com o suporte da plataforma online do $G$ Suite for Education às práticas educativas.

A motivação deste estudo está relacionada a trajetória dos autores que atuam como docentes e integrantes do Grupo de Pesquisa - Núcleo de Pesquisa em Comunicação e Tecnologia (NUCA/UFS), e pesquisam na perspectiva da temática aqui abordada. Assim, foi despertado o interesse em investigar as possíveis potencialidades do ensino hibrido e das TDIC ao serem utilizadas em atividades escolares para a aprendizagem dos estudantes.

O trabalho é pertinente, pois aborda reflexões sobre papel do professor diante do atual cenário educacional e contribui para a difusão do conhecimento, para quem procura propostas que envolvam práticas de Língua Portuguesa que integrem o uso do ensino híbrido e das TDIC no contexto educacional.

Trata-se de uma pesquisa de natureza qualitativa do tipo descritiva. Segundo Moreira e Caleffe (2008, p. 73), "[...] a pesquisa qualitativa explora as características dos indivíduos e cenários que não podem ser facilmente descritos numericamente". É descritiva quanto aos objetivos, de acordo com Gil (2008), esse tipo de estudo habitualmente é realizado por pesquisadores das Ciências Sociais que se preocupam em descrever a prática. Com marco teórico baseado em Bacich, Tanzi Neto e Trevisani (2015), Ferrete (2020), Santaella (2014). Assim,

${ }^{2} \mathrm{~A}$ rotação por estações é um modelo do ensino híbrido baseada em criar diferentes ambientes dentro da sala de aula e formar uma espécie de circuito, permitindo que os estudantes abordem determinado conteúdo de diferentes maneiras. 
para uma melhor compreensão, este texto, está organizado em quatro seções para detalhar o estudo.

A primeira seção se refere à introdução, ora apresentada, em que consta a apresentação do tema, o problema, o objetivo geral, a motivação, a justificativa e o percurso metodológico do trabalho.

$\mathrm{Na}$ sequência, a segunda seção, traz algumas reflexões sobre a tecnologia digital de informação e comunicação: desafios e possibilidades para a prática docente, alinhada a proposta da Base Nacional Comum Curricular - BNCC ${ }^{3}$, enfatizando a $5^{\text {a }}$ competência que trata da cultura digital.

A terceira seção, apresenta uma breve discussão sobre a as metodologias ativas e a aprendizagem no ensino híbrido. Na sequência, aborda a personalização de ensino da Língua Portuguesa potencializada através do uso das TDIC e do ensino híbrido no contexto do ensino fundamental, com descrição das atividades desenvolvidas na metodologia rotação por estações, visando o aluno como centro do processo e o professor como mediador.

Quanto a quarta seção, adentra nos resultados e discussões advindos da aplicação do questionário com os alunos. Por fim, a última seção é dedicada à elaboração das considerações finais da pesquisa, onde foi retomado o problema, considerando as principais ideias discutidas sobre o uso do ensino hibrido e das TDIC na trajetória teórico-metodológica, com base nos resultados empíricos e nas inferências dos autores, visando alcançar o objetivo proposto neste trabalho.

\section{Tecnologia digital de informação e comunicação: desafios e possibilidades para a prática docente}

As tecnologias digitais estão cada vez mais reconfigurando a prática docente, os professores estão sendo desafiados, pelo próprio contexto educacional e político, a incorporar os recursos tecnológicos no trabalho pedagógico, visando o desenvolvimento de competências digitais, como preconiza a Base Nacional Comum Curricular - BNCC (BRASIL, 2017).

No documento normativo BNCC, a Cultura Digital é concebida como uma competência que deve ser desenvolvida no aluno ao longo da Educação Básica, e para que isso ocorra, o professor assume o papel de mediador do processo de ensino e aprendizagem, norteando seus alunos diante do uso do digital, objetivando o desenvolvimento de

\footnotetext{
${ }^{3} \mathrm{~A}$ Base Nacional Comum Curricular (BNCC) é um documento de caráter normativo que define o conjunto orgânico e progressivo de aprendizagens essenciais que todos os alunos devem desenvolver ao longo das etapas e modalidades da Educação Básica.
} 
competências para as profissões do futuro. Como demostrado na $5^{a}$ competência geral do documento:

Compreender, utilizar e criar tecnologias digitais de informação e comunicação de forma crítica, significativa, reflexiva e ética nas diversas práticas sociais (incluindo as escolares) para se comunicar, acessar e disseminar informações, produzir conhecimentos, resolver problemas e exercer protagonismo e autoria na vida pessoal e coletiva. (BRASIL, 2018, p. 9)

Observa-se a pertinência da $5^{\text {a }}$ Competência da Base ao tratar da inserção das TDIC na educação, por ser um fenômeno contemporâneo que pode potencializar as práticas pedagógicas, enriquecendo o conhecimento e promovendo novas formas de diálogo entre o professor e o aluno. Entretanto, quanto a inclusão digital no contexto educacional, precisamos considerar alguns fatores que dificultam essa concretização, como apontam Santos, Ferrete e Alves (2020, p.24):

\footnotetext{
O cenário educacional brasileiro caminha a passos lentos em busca da inclusão digital no âmbito escolar. Isso ocorre seja por falta de recursos tecnológicos nas unidades escolares, ou por problemas envolvendo a formação inicial de professores que não tiveram preparação para lidar com as novas TDIC ou pela qualidade do acesso à internet que é disponibilizada para as escolas [...]
}

Diante do exposto, percebe-se que, mesmo com os avanços tecnológicos e a implementação de políticas públicas educacionais, existe uma lacuna a ser preenchida pois, tanto os recursos tecnológicos quanto a formação docente para o uso da tecnologia digital ainda ocorrem de forma precária. No que diz respeito à carência na formação docente, Gatti (2010) enfatiza que os saberes relacionados a tecnologia no ensino estão praticamente ausentes nas licenciaturas.

Por outro lado, os alunos que por natureza nasceram e se desenvolvem nesse contexto tecnológico, lidam muito bem com os avanços e acompanham a evolução na palma da mão com seus dispositivos móveis. E, é dentro dessa perspectiva que Carvalho (2018, p.33) enfatiza que "a formação de professores não pode descurar as metodologias ativas, os jogos digitais educativos, a gamificação e os aplicativos nas mais diversas finalidades".

De acordo com Ferrete e Ferrete (2019, p.71), "há necessidade de se pensar nas diversas possibilidades de proporcionar inclusão digital desses alunos com a integração das tecnologias móveis no ensino". A aprendizagem potencializada através das tecnologias digitais é centrada num processo continuo de interatividade, que por sua vez, potencializa o aprender junto, a troca de experiência, o compartilhamento de dados, originando um processo de ensino e aprendizagem num ambiente dinâmico, que possibilita inovação e colaboração. No que diz respeito à interatividade, Santaella (2014, p.18) destaca que 
[...] é a característica central de toda a cultura do computador. Se não desenvolvermos treinamento, de que tipo for, por experimentação ou por orientação, para o uso das interfaces no mundo de múltiplas telas que nos é oferecido, as telas permanecem em escuro silêncio [...]

Ferrete (2010) chama atenção para a responsabilidade das instituições de ensino, em propor mudanças para que se possa integralizar as tecnologias, tanto como recurso pedagógico, quanto para fins de formação e reflexão, além da necessidade dos docentes proporem novas estratégias de ensino, que possam ser potencializadas com as experiências incorporadas através das tecnologias digitais.

Inovar na sala de aula, com o uso de recursos digitais tem exigido uma postura diferenciada do professor, que por sua vez, diante aplicação de uma metodologia ativa, assume papel de mediador entre o aluno e o conhecimento a ser construído. Nessa perspectiva, o ensino hibrido dinamiza as relações entre os atores da aprendizagem, no caso, professor e aluno, potencializando de maneira colaborativa, a forma como se ensina e se aprende.

\section{Metodologias ativas e a aprendizagem no ensino híbrido}

Em um sentido amplo, aprendemos ativamente desde nosso nascimento, e é possível aprender de diversas formas, inclusive através da educação tradicional ${ }^{4}$. Porém, diante das rápidas transformações sociais questiona-se sobre a efetividade do ensino pautado na transmissão de conteúdo, a escola precisa exercer um novo papel em uma realidade onde os alunos não esperam aprender para fazer, aprendem enquanto fazem.

Freire (2014, p. 47) enfatiza que "saber ensinar não é transferir conhecimento, mas criar as possibilidades para a sua própria produção ou sua construção", atenta que o professor deve entrar na sala de aula aberto a indagações, curiosidade, perguntas dos alunos e exemplifica

\footnotetext{
Como professor de formação docente não posso esgotar minha prática discursando sobre a teoria da não extensão do conhecimento. Não posso apenas falar bonito sobre as razões epistemológicas e políticas da teoria. O meu discurso sobre a teoria deve ser o exemplo concreto, prático, da teoria. (FREIRE, 2014, p.47, grifo nosso)
}

Nesse sentido, é importante refletir sobre uma mudança gradativa no cenário da educação tradicional, considerando a observação e apropriação do espaço de aprendizagem, a

\footnotetext{
${ }^{4}$ Adotaremos neste trabalho o termo educação tradicional ou ensino tradicional, aquele cuja ênfase está na pura transmissão do conhecimento, onde o professor está ativo e o aluno passivo no processo de ensino e aprendizagem.
} 
relação aluno-professor, assim como o papel desempenhado por cada um, e demais agentes que compõem esse contexto. Partindo dessa perspectiva, as metodologias ativas de aprendizagem propõem mudanças ao inserir o estudante no centro da discussão do processo ensino e aprendizagem. E, dessa forma, levando em consideração o seu interesse, colocam-no como protagonista, sujeitos ativos e autônomos no processo de construção do conhecimento.

Vale ressaltar que, ao mencionarmos as metodologias ativas na educação, não podemos esquecer os principais autores que defenderam, desde o século XX, uma educação pautada na aprendizagem. A Escola Nova de John Dewey, nos anos de 1930, apresenta uma extensa discussão sobre a divergência entre a educação tradicional centralizada no conteúdo e no professor e a educação progressista, protagonizada pelo aluno valorizando seus conhecimentos prévios. Dewey enfocava a necessidade de estreitar a relação entre teoria e prática, e apoiava a ideia do aluno como sujeito ativo no processo de ensino e aprendizagem a partir do conceito "aprender fazendo" e "aprender a aprender".

Trazendo para os dias atuais, "aprender fazendo" equivale a "botar a mão na massa", por meio da prática, os alunos sentem-se estimulados pelo protagonismo e demostram mais interesse e engajamento no desenvolvimento das atividades, tornando mais compreensível o aprendizado. Algumas metodologias têm sido utilizadas para promover a aprendizagem ativa, em várias possibilidades se coadunam com as TDIC, como o ensino híbrido. Percebe-se que essas práticas dialogam com o perfil dos nativos digitais, pois favoreçam o protagonismo dos alunos, que participam ativamente de maneira colaborativa, interagindo com os pares e buscando solucionar as atividades propostas. Assim, ao ressignificar as suas práticas, o professor desempenha o papel de mediador conectando os estudantes com novas formas de conhecimento, contribuindo para a realização da construção autônoma e a formação dos cidadãos críticos e reflexivos.

Assim, o ensino híbrido integra educação à tecnologia, transformando a maneira de ensinar do professor e a forma de aprender dos alunos. Esta abordagem de ensino também pode ser personalizada e colaborativa; estar aliada ao uso das TDIC e propiciar momentos de aprendizagem e troca que ultrapassam as barreiras da sala de aula. Conforme elucida Mo$\operatorname{ran}(2015, \mathrm{p} .22)$

\footnotetext{
Híbrido significa misturado, mesclado, blended. A educação sempre foi misturada, híbrida, sempre combinou vários espaços, tempos, atividades, metodologias, públicos. Esse processo, agora, com a mobilidade e a conectividade, é muito mais perceptível, amplo e profundo: é um ecossistema mais aberto e criativo. Podemos ensinar e aprender de inúmeras formas, em todos os momentos, em múltiplos espaços. Híbrido é um conceito rico, apropriado e complicado. Tudo pode ser misturado, combinado, e podemos, com os mesmos ingredientes, preparar diversos "pratos", com sabores muito diferentes.
} 
Segundo o autor, híbrido significa misturado, mesclado, blended"’. É um mix, mistura o físico e o digital, o presencial e o virtual partindo da premissa de que há várias formas de aprender e diferentes maneiras de ensinar. Para Moran (2015, p.16), "essa mistura, entre sala de aula e ambientes virtuais é fundamental para abrir a escola para o mundo e para trazer o mundo para dentro da escola". Desse modo, o ensino híbrido pode permitir que o aluno se torne mais responsável pela sua aprendizagem considerando as diversas formas de aprender e ensinar, conforme demostrado na Figura 1.

Figura 1 - Possibilidades de ensinar e aprender com o Ensino Híbrido

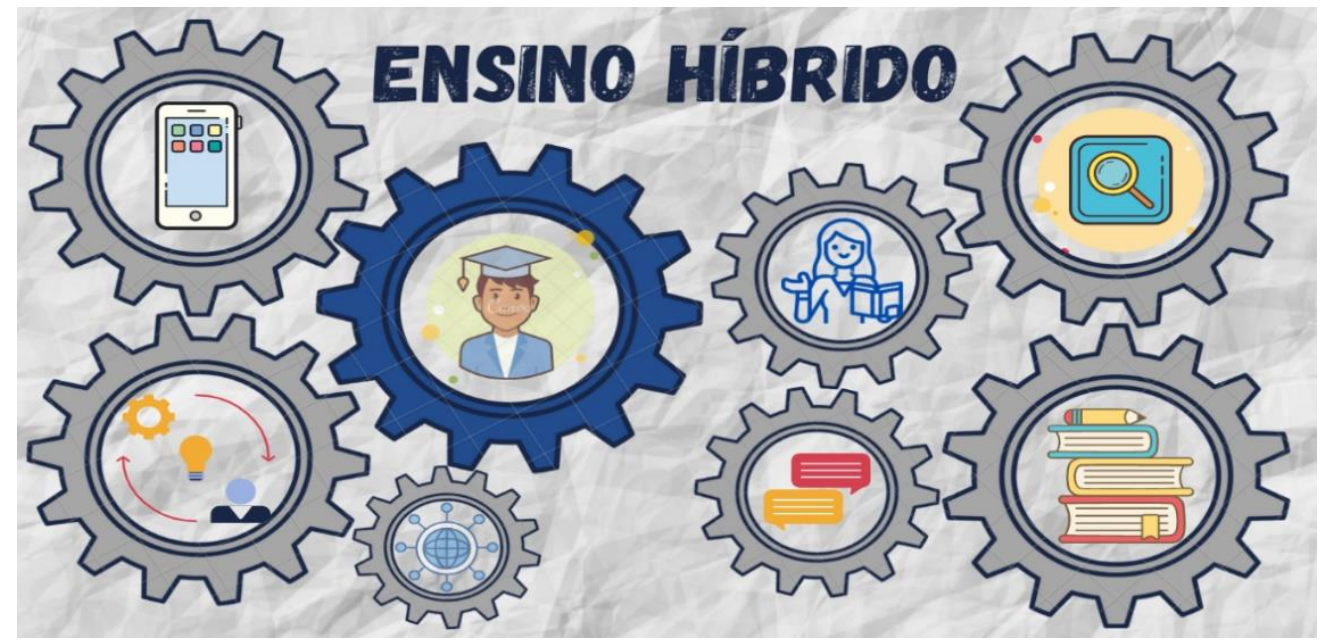

Fonte: Elaboração dos autores (2020).

Embasada pelo livro Ensino Híbrido personalização e tecnologia na educação, (Bacich et al., 2015).

Como o foco do ensino híbrido está voltado para a aprendizagem, há uma ressignificação dos papéis dos alunos e dos professores; $\mathrm{O}$ aluno ativo, estuda os conteúdos em diversos espaços além da escola, sendo estimulado e desafiado a aprendizagens mais ativas e colaborativas, no ambiente escolar. Outro ponto que se destaca no ensino híbrido são as atividades colaborativas integradas as tecnologias, por estarem imersos no mundo virtual, os alunos sentem-se estimulados, assumindo uma postura mais participativa, afinal, aprender com os pares torna-se ainda mais significativo quando há um objetivo comum a ser alcançado pelo grupo.

Segundo Bachic et al. (2015), o ensino híbrido organiza-se em alguns modelos que integram a sala de aula tradicional e outros mais disruptivos, onde ela não está presente. Os modelos sala de aula invertida, rotação por estação e laboratório rotacional compreendem as

${ }^{5}$ Tradução de blended, misturado. 
aulas presenciais com atividades online. Os modelos "rotação individual", "flex", "a la carte" e "virtual enriquecido" têm ênfase na aprendizagem online. É importante ter clareza que o foco do ensino híbrido é a aprendizagem do aluno, portanto para implementação, o professor necessita estimular o protagonismo do aluno, e este precisa assumir uma postura ativa no processo de aprendizagem.

Nessa perspectiva, Bacich e Moran (2018), chamam a atenção sobre os conceitos de aprendizagem ativa e aprendizagem híbrida, conforme demonstrado no mapa da Figura 2.

Figura 2 - Mapa com os Conceitos de Aprendizagem segundo Bacich \& Moran

\section{APRENDIZAGEM}

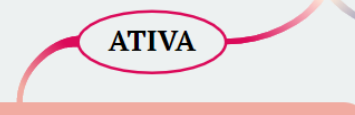

As metodologias ativas dão ênfase ao papel protagonista

do aluno, ao seu envolvimento direto, participativo e

reflexivo em todas as etapas do processo, experimentando, desenhando, criando, com orientação do professor.

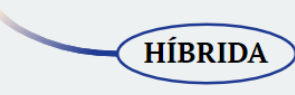

\section{HIBRIDA}

Destaca a flexibilidade, a mistura e compartilhamento de espaços, tempos, atividades, materiais, técnicas e tecnologias que compõem esse processo ativo.

Fonte: Elaboração dos autores (2020),

com base na obra Metodologias ativas para uma educação inovadora, (Bacich; Moran, 2018).

A partir dos conceitos, percebemos que a aprendizagem ativa enfatiza o protagonismo do aluno com a sua participação em todas as etapas do processo, e o papel do professor como orientador ou mediador ganha maior relevância. Enquanto na aprendizagem híbrida enfatiza-se a flexibilização e o compartilhamento, trazendo várias possibilidades de combinações entre o físico e o digital, sempre centrado na aprendizagem ativa do aluno.

Para Moran (2015), a tecnologia integra os espaços e os tempos, o ensinar e aprender acontece numa interligação simbiótica, profunda, constante entre o mundo físico e o digital. O autor enfatiza que não são dois mundos ou espaços, mas um espaço estendido, uma sala de aula ampliada; a educação formal é cada vez mais blended, misturada, híbrida, pois não acontece só no espaço físico da sala de aula, mas nos múltiplos espaços do cotidiano, que incluem os digitais.

Desta forma, escolheu-se analisar neste artigo como o ensino híbrido, na perspectiva da rotação por estações e inserção das TDIC, aparece como um grande potencial para tornar as aulas de Língua Portuguesa mais dinâmicas, possibilitando a criação de um ambiente de estudo interativo e colaborativo. 


\section{Personalização de ensino da Língua Portuguesa potencializada através do ensino hí-} brido e da inserção das TDIC

O ensino personalizado é uma proposta pedagógica que promove o desenvolvimento do estudante de maneira individual. $\mathrm{Na}$ aprendizagem personalizada, entende-se que os estudantes aprendem de formas diferentes, levando em conta as características pessoais, o interesse e o conhecimento prévio. Nessa perspectiva, a personalização exige uma postura diferenciada do professor, que precisará dinamizar as suas práticas buscando explorar os pontos fortes dos alunos e trabalhar para corrigir as áreas em que eles demonstram dificuldades.

A personalização do ensino, as metodologias ativas e o ensino hibrido estão conectados, assim, apresentaremos uma prática pedagógica, na perspectiva da rotação por estações, destacando a importância do uso das TDIC como uma possibilidade para tornar as aulas de Língua Portuguesa mais personalizadas, com objetivo de inovar e enriquecer o processo de ensino e aprendizagem.

Segundo Bacich e Moran (2018, p.4), "a junção de metodologias ativas com modelos flexíveis e híbridos traz contribuições importantes para o desenho de soluções atuais para os aprendizes de hoje”. Nesse sentido, a aula foi planejada utilizando uma das estratégias didáticas do ensino híbrido, a rotação por estações, a fim de trabalhar o assunto: figuras de linguagem. O intuito foi apresentá-lo de forma diversificada possibilitando ao aluno experimentar colaborativamente com os colegas as diferentes abordagens, promovendo maior engajamento entre eles na construção do aprendizado, pois aprender com os pares torna-se ainda mais significativo quando há um objetivo comum a ser alcançado pelo grupo. Com o objetivo de formar equipes diversificadas foram organizados estrategicamente cinco estações compostas por seis alunos. O estabelecimento de critérios para a formação das equipes favoreceu a dinâmica da prática e a qualidade da aprendizagem coletiva. Conforme Marcondes e Ferrete (2020, p. 209-210),

É importante trabalhar com esses estudantes a aprendizagem colaborativa, que pode acontecer entre pares ou em grupos, presenciais ou virtuais. Nesse contexto, os alunos participam ativamente do processo de ensino e aprendizagem, quando dois ou mais alunos aprendem algo junto, colaborando com o aprendizado entre o grupo, compartilhando o que sabem e trocando informações em tempo real.

O ensino híbrido, através da metodologia rotação por estações promove essa conexão entre os alunos. Ao desenvolverem as atividades propostas em cada estação, eles discutem, 
compartilham as informações entre os pares e participam ativamente do processo de ensino e aprendizagem.

Nessa estratégia didática há três momentos importantes: a interação entre alunos e professor (momento em que ele pode explicar o conteúdo e a atividade, tirar dúvidas e provocar reflexões), atividades colaborativas (em que os estudantes organizam e desenvolvem a tarefa proposta em cada estação, discutem as questões entre os pares para trocar as experiências), como sugestão pode-se trabalhar nesse momento a metodologia Pare, Pareie e Compartilhe - PPC; e a inserção da tecnologia (que pode incluir em todas as estações ou apenas em uma, através do uso de celular ou computador, desenvolvendo exercícios online, pesquisas, games, vídeos, músicas, entre outros).

O desenvolvimento da atividade de cada estação não segue uma sequência específica, e as tarefas realizadas nos grupos são independentes, porém precisam funcionar de forma integrada. De modo que, ao final da aula, todos tenham a oportunidade de acessar o mesmo conteúdo sob diferentes formas de aprendizagem, conforme se observa na Figura 3.

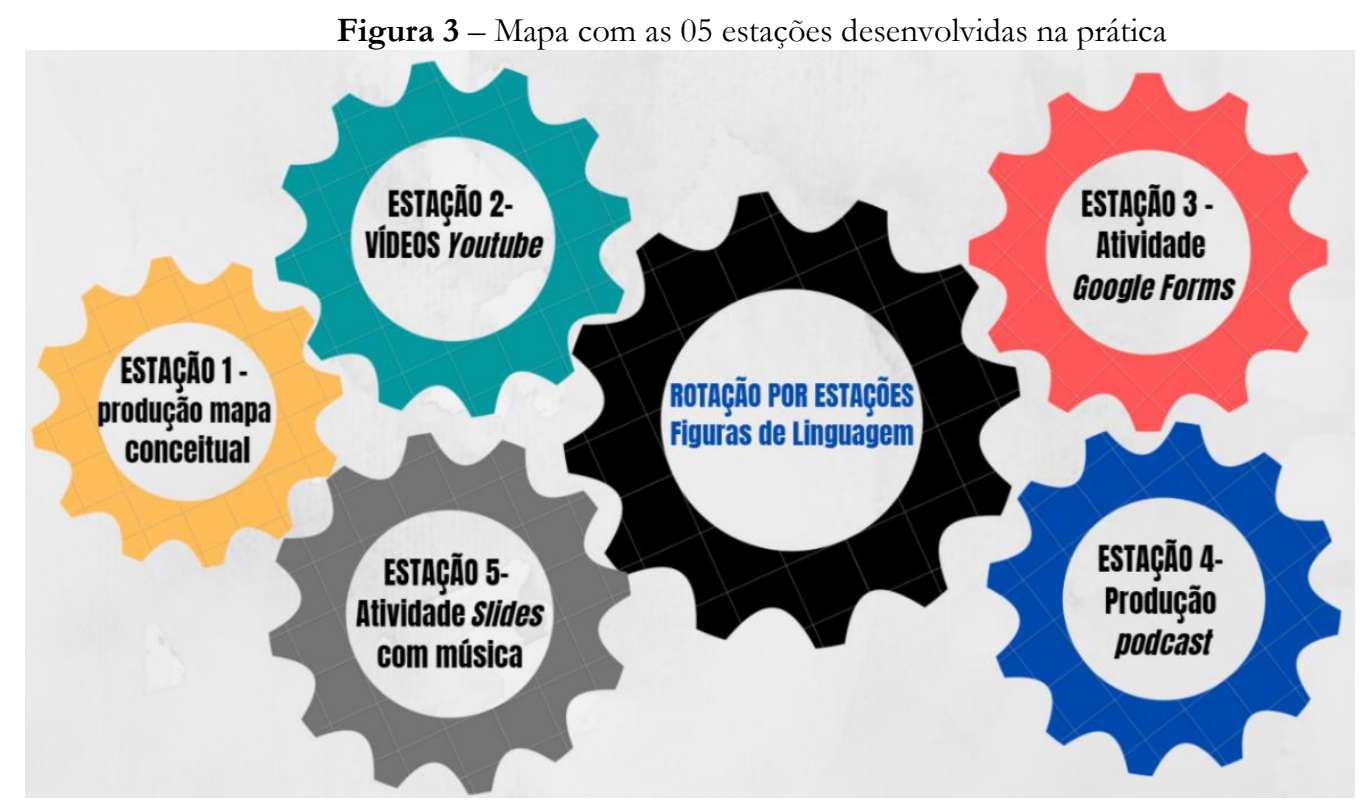

Fonte: Elaboração dos autores (2020).

As estações foram planejadas com o objetivo de promover a interação entre os alunos na execução de cada atividade, buscando proporcionar o desenvolvimento da escuta, compartilhamento, interação, produção textual, apoio e encorajamento à fala, à leitura e à escrita. Além disso, manteve os alunos atentos e motivados, pois permanecem um tempo relativamente curto em cada estação: de 15 minutos. A rotação das atividades permite que alunos em diferentes níveis trabalharem juntos potencializando o aprendizado entre os pares, também possibilita que façam uso compartilhado da tecnologia, uma maneira de engajar a turma. 
Percebe-se que, ao longo da atividade, o aluno encontra-se ativo no processo e o papel do professor é de mediador, circulando entre as estações e ajudando as equipes a caminharem em direção ao objetivo principal, bem como motivar a participação de estudantes que não se sintam integrados, promovendo intervenções personalizadas.

Importante salientar que, as atividades planejadas para cada uma das estações, devem estar coerentes com o objeto de conhecimento trabalhado na aula, com flexibilidade para atender diferentes ritmos de aprendizagem. É interessante manter o componente lúdico para motivar o desenvolvimento das tarefas e deve evitar atividades repetitivas, importante colocar em cada estação uma orientação visível que informe a sequência em que cada equipe deve rotacionar e, as atividades devem ser realizáveis no tempo previsto, como se pode observar no quadro 1.

Quadro 1 - Atividades desenvolvidas nas estações

\begin{tabular}{|c|c|}
\hline ESTAÇÃO & INSTRUÇÕES PARA OS ALUNOS \\
\hline $\begin{array}{l}\text { ESTAÇÃO } 01 \\
\text { PRODUÇÃO MAPA } \\
\text { CONCEITUAL }\end{array}$ & $\begin{array}{l}\text { Nesta estação vocês farão a leitura dos materiais anexados no Classroom } \\
\text { sobre FIGURAS DE LINGUAGEM, após isso devem: } \\
1 \text { - Criar um mapa conceitual com as Figuras de Linguagem: } \\
\text { personificação, comparação, metáfora, metonímia, hipérbole e sines- } \\
\text { tesia. } \\
2 \text { - Fotografar e anexar a foto nesta atividade. } \\
\text { Material: papel canson, lápis, borracha, régua, canetinhas, Chromebooks } \\
\text { com acesso à internet e smartphones. } \\
\text { Tempo: } 15 \text { minutos. }\end{array}$ \\
\hline $\begin{array}{l}\text { ESTAÇÃO } 02 \\
\text { VÍDEOS YOUTUBE }\end{array}$ & $\begin{array}{l}\text { Abaixo vocês encontrarão vídeos distintos sobre FIGURAS DE LIN- } \\
\text { GUAGEM. } \\
\text { Sigam os passos abaixo: } \\
1 \text { - Cada integrante deverá assistir } 01 \text { ou mais vídeos; } \\
2 \text { - Ao final vocês utilizarão a metodologia: PPC (Pare, pareie e com- } \\
\text { partilhe) para trocar as informações assistidas; } \\
3 \text { - Anotem-as, pois serão úteis para as próximas estações. } \\
\text { Material: Fones e Chromebooks com acesso à internet. } \\
\text { Tempo: } 15 \text { minutos. }\end{array}$ \\
\hline $\begin{array}{l}\text { ESTAÇÃO } 03 \\
\text { ATIVIDADE NO GOO- } \\
\text { GLE FORMS }\end{array}$ & $\begin{array}{l}\text { VAMOS PRATICAR? Acessem o Classroom e resolvam os exercícios } \\
\text { propostos. Antes de responder, PARE, PENSE E PAREIE as infor- } \\
\text { mações com os colegas. TODOS DEVERÃO RESPONDER ao } \\
\text { questionário. } \\
\text { Material de apoio em anexo para eventuais dúvidas. } \\
\text { Material: Chromebooks com acesso à internet. } \\
\text { Tempo: } 15 \text { minutos. }\end{array}$ \\
\hline ESTAÇÃO 04 & $\begin{array}{l}\text { Pesquise sobre as figuras de linguagem COMPARAÇÃO x METÁ- } \\
\text { FORA, em seguida acesse o link: gg.gg/gravarpodcast para criar um } \\
\text { podcast explicando as semelhanças e as diferenças entre elas, LEMBRE- }\end{array}$ \\
\hline
\end{tabular}




\begin{tabular}{|c|c|}
\hline PRODUÇÃO PODCAST & $\begin{array}{l}\text { SE DE CITAR EXEMPLOS. } \\
\text { Material: Livro didático, fones e Chromebooks com acesso à internet. } \\
\text { Tempo: } 15 \text { minutos. }\end{array}$ \\
\hline $\begin{array}{l}\text { ESTAÇÃO } 05 \\
\text { ATIVIDADE COM MÚ- } \\
\text { SICA } \\
\text { APRESENTAÇÃO GOO- } \\
\text { GLE (SLIDES) }\end{array}$ & $\begin{array}{l}\text { Agora vocês deverão fazer uma apresentação (use o Google apresen- } \\
\text { tações), trabalhando os conceitos das Figuras de Linguagem e utili- } \\
\text { zando exemplos de músicas (tente inserir trechos das músicas) para } \\
\text { cada uma delas: } \\
\text { 1.PERSONIFICAÇÃO OU PROSOPOPEIA; } \\
\text { 2.METONÍMIA; } \\
\text { 3.HIPÉRBOLE; } \\
\text { 4.SINESTESIA. } \\
\text { SUGESTÃO: PARA OTIMIZAÇÃO DO TEMPO, TRABALHEM } \\
\text { COLABORATIVAMENTE, COMPARTILHEM A APRESENTA- } \\
\text { ÇÃO COM OS COLEGAS DO GRUPO E CONSTRUAM JUN- } \\
\text { TOS! } \\
\text { Material: Livro didático, Chromebooks com acesso à internet. } \\
\text { Tempo: } 15 \text { minutos. }\end{array}$ \\
\hline
\end{tabular}

Fonte: Elaboração dos autores (2020)

Ao planejar cada atividade, foi importante considerar o perfil dessa geração de nativos digitais, pois eles demostram interesse e facilidade ao utilizar a tecnologia. Na perspectiva de compreender as possíveis potencialidades do ensino híbrido e das TDIC ao serem utilizados em práticas educativas, fez-se imprescindível um estudo de campo com 29 alunos do $8^{\circ}$ ano do Ensino Fundamental, de uma escola particular de Educação Básica do município de Aracaju-SE.

A aplicação do questionário foi fundamental para entender a percepção dos alunos ao usarem a metodologia da rotação por estações, do ensino híbrido em sala de aula, e também investigar a construção do conhecimento com a inserção das tecnologias, contemplando os diferentes estilos de aprendizagem dos estudantes.

\section{Resultados da pesquisa}

Dando sequência ao andamento da pesquisa e aos instrumentos de coleta de dados, inicialmente, verificou-se que o perfil dos estudantes participantes da pesquisa, feita a partir de um questionário no Google Forms, estão entre as faixas etárias de 12 e 14 anos.

Ao serem questionados sobre como classificariam (numa escala de 1 a 5 ) a aula sobre figuras de linguagem, com a metodologia rotação por estações, 1 aluno $(3,4 \%)$ classificou com nota (2,0); 06 alunos (20,7\%) nota 3,0; 10 alunos (34,5\%) nota 4,0 e 12 alunos (41,4\%) deram nota máxima $(5,0)$, conforme se observa no Gráfico 1. 
Gráfico 1 - Classificação da aula rotação por estações

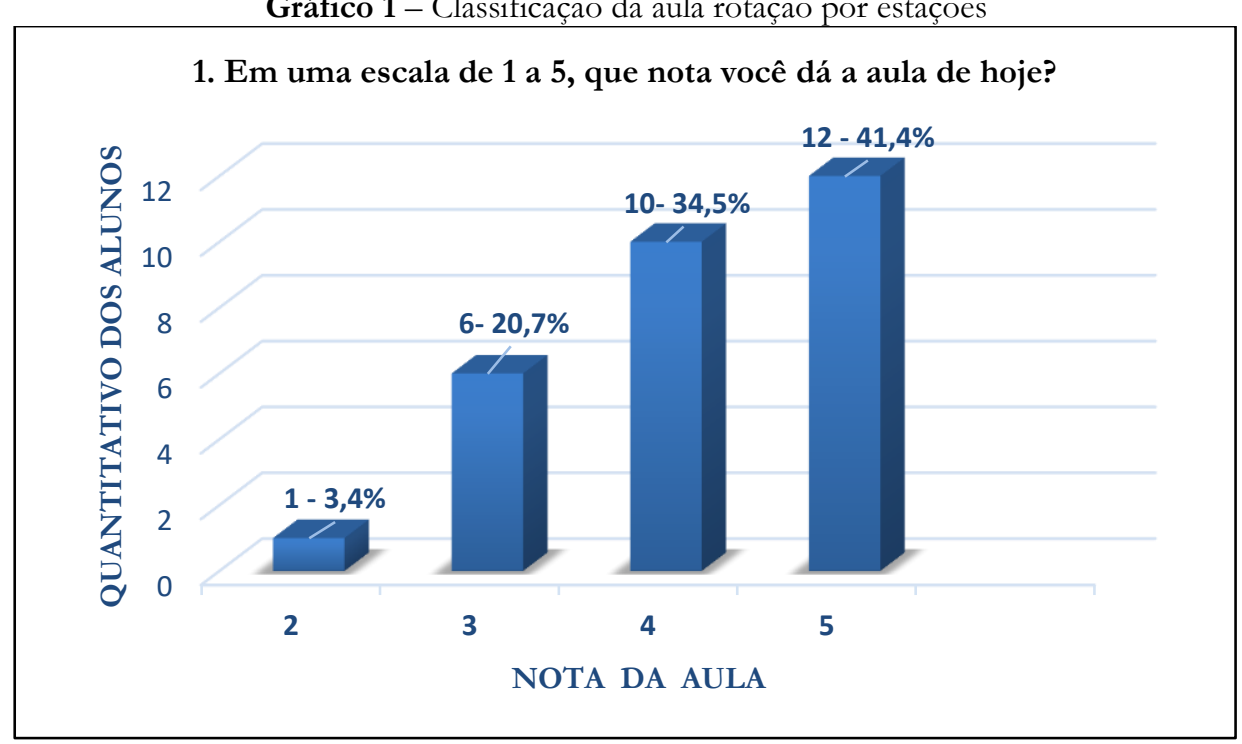

Fonte: autores (2020).

Conforme o gráfico que representa os dados coletados, $75,9 \%$ dos alunos demonstram haver uma boa aceitação dos alunos pela estratégia metodológica da aula, abordando o objeto de conhecimento figuras de linguagem, utilizando a técnica da rotação por estações, do ensino híbrido e a tecnologia com o intuito de tornar a aula dinâmica e interativa. Importante ressaltar que a tecnologia possibilita outras formas de ensinar e aprender, com perspectivas educacionais para professores e alunos.

A pesquisa buscou ainda identificar a estação que tiveram maior dificuldade de compreensão, 11 alunos, correspondente a 37,9\%, responderam que sentiram dificuldade na estação 4, na produção do podcast, seguindo de 6 alunos (20,7\%), que mencionaram dificuldade na estação 3, referente a resolução dos exercícios. Houve um empate de 5 alunos (17,2\%), nas estações 1 e 5, referente a criação do mapa conceitual e vídeos, respectivamente; e 2 alunos (7\%) mencionaram sentir dificuldade de compreensão na estação 2. Na sequência, quanto a estação que mais agradou, 9 alunos (31\%) mencionaram a estação 2, seguida da estação 4, escolhida por 8 alunos (27,6\%); 6 alunos, correspondente a 20,7\%, escolheram a estação 5; 4 alunos (13,8\%), preferiram a estação 1; e, finalmente, 2 alunos 6,9\%, escolheram a estação 3 com conforme Gráficos 2. 


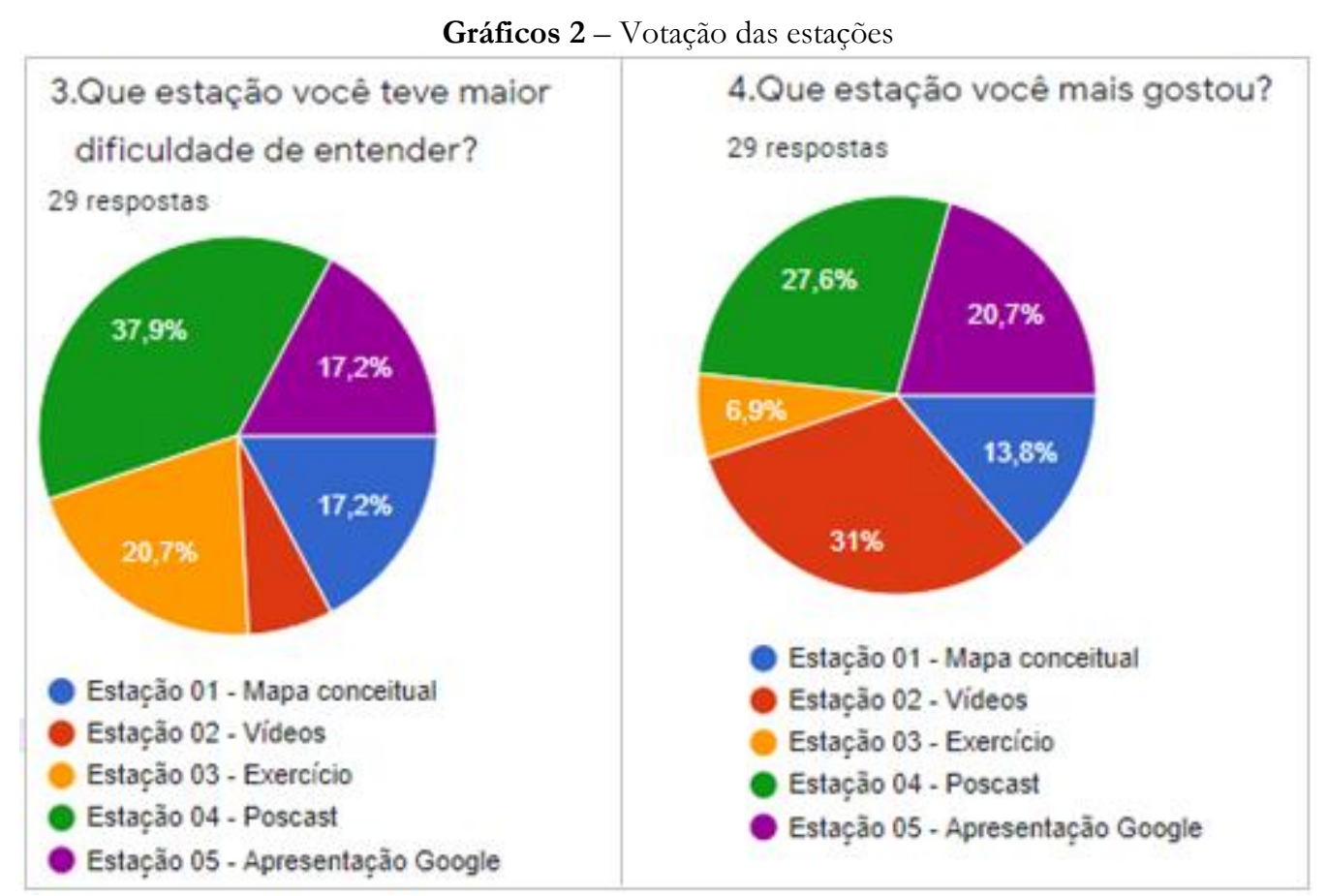

Fonte: Elaboração dos autores (2020).

Diante do exposto, identifica-se que a estação 2, em que os alunos assistiram aos vídeos foi a que apresentou menor dificuldade de compreensão e a que mais agradou a turma. Embora a maioria dos alunos tenha apresentado dificuldade de compreensão da tarefa solicitada na estação 4, a criação do podcast foi a segunda atividade que mais agradou os estudantes. Quanto a estação 3, foi a segunda atividade com maior grau de dificuldade de entendimento e a que menos agradou.

Esta análise nos permitiu inferir que os estudantes demonstraram maior interesse em participar das estações que apresentaram conectividade com seu dia a dia, pois geralmente eles já fazem uso do serviço de streaming ${ }^{6}$ de áudio e vídeo. O Professor pode aproveitar essa aceitação para desenvolver atividades que usem o podcasts de maneira significativa. Outros benefícios, além de trabalhar a oralidade e a escuta, é que os alunos participam ativamente do processo de aprendizagem e passam a ser produtores do conhecimento.

Trazendo para um contexto de aprendizagem, ao serem questionados se compreenderam o assunto figura de linguagem trabalhado na aula desenvolvida a partir da rotação por estações, a maioria, 17 alunos, correspondente a 58,6\% respondeu que sim, enquanto 10 alunos, equivalente a 34,5\% compreendeu mais ou menos; e, apenas 2 alunos (6,9\%) mencionaram que não compreenderam o assunto. Embora, ao perguntar se eles preferiam a aula

${ }^{6}$ Todo o conteúdo multimídia que possa ser visto ou ouvido sem precisar fazer download e que possa ser consumido durante o seu carregamento é streaming. 
com a inserção da tecnologia nas práticas educativas, identificou-se que todos os alunos responderam que preferem aula com o uso da tecnologia, vide Gráficos 3.

Gráficos 3 - Aprendizagem e aula com inserção da tecnologia

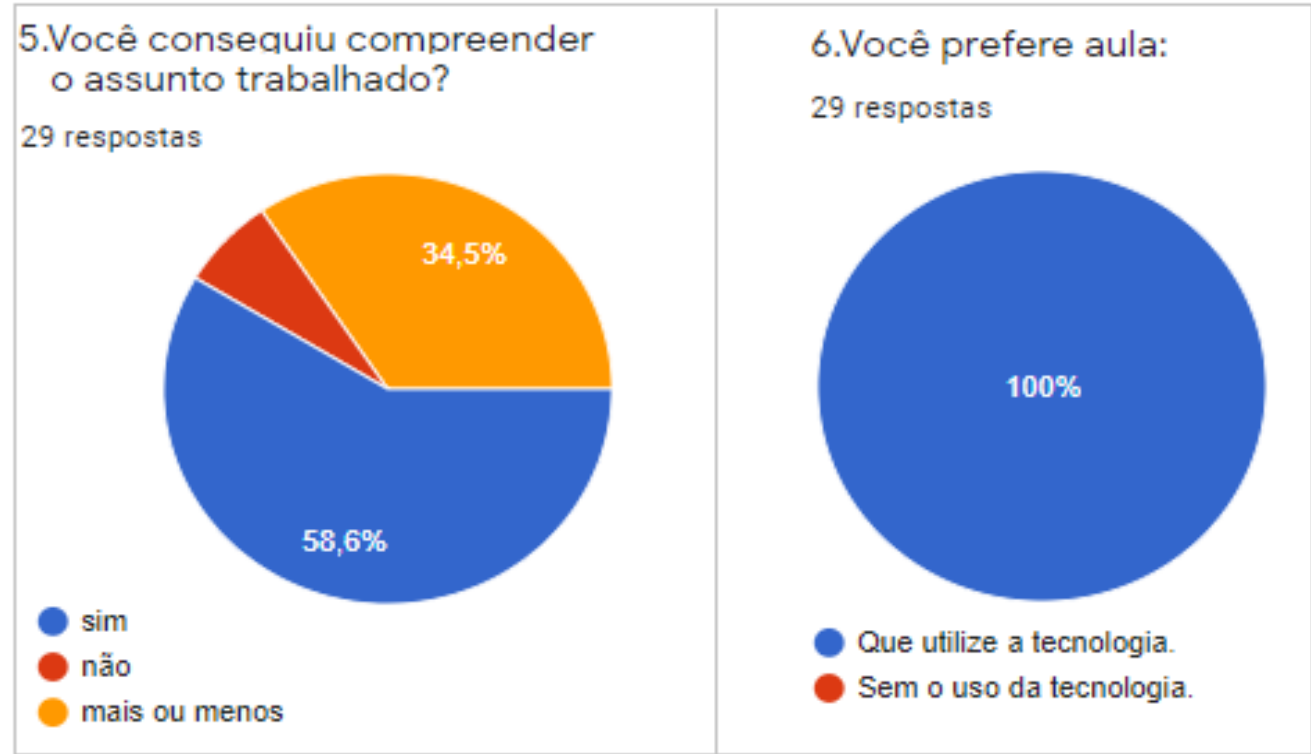

Fonte: autores (2020).

Ao analisar o resultado, infere-se que a estratégia de trabalho do professor, a partir do ensino híbrido com a rotação por estações e a inserção das TDIC, tornou a abordagem do conteúdo mais dinâmico e as atividades desenvolvidas em cada estação contribuíram para o processo de aprendizagem dos alunos. Nota-se ainda, pelo perfil desses estudantes, que vivem imersos no mundo virtual, que o uso da tecnologia é um fator motivador para o desenvolvimento das atividades propostas pelo professor de Língua Portuguesa.

Ainda no contexto de aprendizagem com a inserção da tecnologia nas práticas educativas, identificou-se entre os alunos que, 24 alunos, representando 82,8\% responderam que preferem aulas em que eles participam do processo educativo desenvolvendo diversas atividades, e, 5 alunos, $17,2 \%$ preferiram aula expositivas quando o professor transmite o conteúdo. Posteriormente, buscou-se identificar quanto ao espaço físico, 28 alunos, representando $96,6 \%$ responderam que preferem as aulas na sala Google, e apenas 1 aluno equivalente a 3,4\% falou que prefere a sala de aula presencial, vide Gráficos 4. 
Gráficos 4 - Resultado práticas educativas com tecnologia

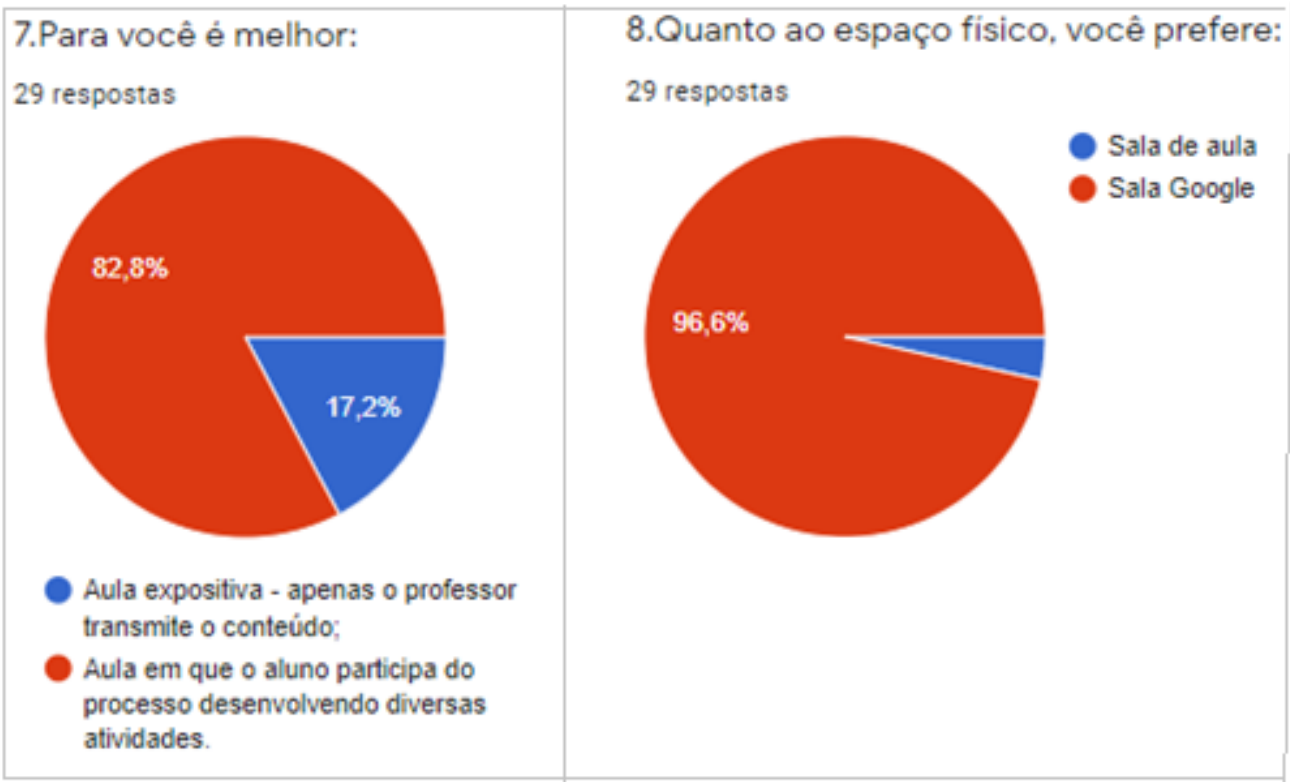

Fonte: Elaboração dos autores (2020).

Observa-se com base nos gráficos apresentados, que a maioria dos alunos prefere participar ativamente das aulas, partindo desta perspectiva, o professor pode potencializar as suas práticas ao inserir as metodologias ativas e adaptá-las de acordo com a realidade vivenciada em suas aulas virtuais ou presencias, podendo aplicar um formulário de avaliação após cada aula ministrada e no momento de registro da presença do aluno, por exemplo. A principal mudança está no papel do docente que passa de protagonista a coadjuvante, enquanto os alunos não são mais receptores passivos e assumem o protagonismo na construção do conhecimento com apoio da mediação do professor no processo de ensino e aprendizagem.

É perceptível ainda, a aprovação dos estudantes quanto a realização das aulas na Sala Google, infere-se que, além do uso dos recursos tecnológicos, é possível tornar o ensino mais produtivo e dinâmico ao utilizar ambiente diferente da sala convencional com estrutura que propicia uma melhor integração e interação entre professores e alunos.

O resultado demostra que, a maioria dos alunos avaliou positivamente as aulas de Língua Portuguesa em que o professor utilizou o ensino hibrido, a partir da metodologia ativa rotação por estações com a inserção das TDIC.

\section{Considerações finais}

O advento da tecnologia tem papel importante nas mudanças que estão ocorrendo em nossa sociedade, diante da velocidade e diversificação do conhecimento e da informação, é imprescindível reconhecer a importância das TDIC na educação, para possibilitar outras 
formas de ensinar e aprender, com perspectivas educacionais tanto para professores quanto para estudantes.

Assim, retomando o problema inicial da pesquisa, que caminho o professor precisa trilhar para inserir o ensino híbrido e a tecnologia digital nas práticas pedagógicas do ensino de Língua Portuguesa? Esta análise nos permitiu inferir que o estudante demonstrou interesse em participar ativamente do processo de ensino e aprendizagem, assim, com planejamento adequado, o professor pode explorar as potencialidades do ensino hibrido e das TDIC para abordar o conteúdo de forma diversificada e tornar o ensino mais dinâmico, além de contribuir para o processo de aprendizagem dos alunos.

Nesse sentido, esperamos que essas informações possam apontar caminhos de reflexão, ajudando a ampliar as possibilidades do uso das tecnologias e das metodologias para desenvolver atividades e motivar a participação dos alunos nas aulas. Vale ressaltar que, em sala de aula o uso da tecnologia deve ser orientado pelo professor, diferente da utilização em seu cotidiano, tendo em vista que são indivíduos consumidores de informações digitais e de tecnologias, geralmente, voltadas para games e redes sociais e diversão.

Entretanto, utilizar o ensino híbrido e inserir as tecnologias em sala de aula não significa uma transformação do ensino. É preciso que o professor identifique a possibilidade pedagógica de cada metodologia e dos recursos tecnológicos, para que estejam em conformidade com a proposta curricular, os objetos de aprendizagem e, ainda, interligados a realidade de seus alunos, em um processo coletivo e colaborativo de construção de conhecimento.

\title{
INFORMATION DIGITAL TECHNOLOGY AND COMMUNICATION AS PEDAGOGICAL RESOURCES AT LÍNGUA PORTUGUESA TEACHING
}

\begin{abstract}
The present work aims to present pedagogical practices from the hybrid teaching in Basic Education, in the perspective of the rotation by seasons, highlighting the importance of the use of Digital Technologies of Information and Communication (TDIC) and the active methodologies for the personalization of the teaching of Portuguese language. Methodologically, it is a qualitative, descriptive research using empirical procedures. The research was carried out with an 8th grade class from a private school in the city of Aracaju-SE / Brazil. As a result, it was identified the possibility of the teacher, when innovating his practice, to increase the level of interaction and motivation of the students in the development of Portuguese Language activities, showing the importance of the use of hybrid teaching and digital technology in the teaching and learning process learning.
\end{abstract}

KEYWORDS: Hybrid Teaching; Portuguese language; Active Methodologies; Digital technologies.

\section{REFERÊNCIAS}

BACICH, L.; TANZI NETO, A.; TREVISANI, F. de M. Ensino bíbrido: personalização e tecnologia na educação. Porto Alegre: Penso, 2015. 
BACICH, L.; MORAN, J. Metodologias ativas para uma educação inovadora - uma abordagem teórico-prática. Porto Alegre: Penso, 2018.

BRASIL. Ministério da Educação. Base Nacional Comum Curricular. Brasília: MEC/SEB, 2017. Disponível em: http://basenacionalcomum.mec.gov.br/images/BNCC publicacao.pdf. Acesso em: 29 abr. 2020.

CARVALHO, A. A. A. Formação docente na era da mobilidade: metodologias e aplicativos para envolver os alunos rentabilizando os seus dispositivos móveis. Revista Tempos e Espaços em Educação, São Cristóvão, v.11, n.1, 2018, p. 25-36. Disponível em: https://doi.org/10.20952/revtee.v11i01.10047. Acesso em: 25 maio 2020.

FERRETE, A. A. S. S. Sala de aula virtual: análise de um espaço vívido na EaD. In: FRANÇA, L. C. M.; FERRETE, A. A. S.; GOUY, G. B. (Org.). Educaşão à distância: ambientes virtuais, TICs e universidades abertas. Aracaju: Criação, 2010. E-book. Disponível em: http://editoracriacao.com.br/wp-content/uploads/2015/12/ticseadlilianneguilherme.pdf. Acesso em: 25 abr. 2019.

FREIRE, P. Pedagogia da autonomia. Saberes necessários à prática educativa. Rio de Janeiro: Paz e Terra, 2014.

GATTI, B. A formação de professores no Brasil: características e problemas. Educação \& Sociedade, Campinas, v, 31, p. 1355-1379, 2010. Disponível em: https://www.scielo.br/pdf/es/v31n113/16.pdf. Acesso em: 30 abr. 2020.

GIL, A. C. Métodos e técnicas de pesquisa social. 6. ed. São Paulo: Atlas, 2008.

MARCONDES, R. M. T; FERRETE, A. A. S. S. Tecnologia digital de informação e comunicação e metodologias ativas na personalização do ensino de redação. Humanidades \& Inovação, v.7, n. 6, 2020, p. 207-2020. Disponível em: https://revista.unitins.br/index.php/humanidadeseinovacao/article/view/2314. Acesso em: 24 jul. 2020.

MOREIRA, H.; CALEFFE, L. G. Metodologia da pesquisa para o professor pesquisador. Rio de Janeiro: Lamparina, 2008.

SANTAELLA, L. A aprendizagem ubíqua na educação aberta. Tempos e Espaços Em Educação, São Cristóvão, v.7, p. 15-22, 2014. Disponível em: https://doi.org/10.20952/revtee.v0i0.3446. Acesso em: 29 abr. 2020.

SANTOS, W. L.; FERRETE, A. A. S. S.; ALVES, M. M. S. A produção do conhecimento sobre Facebook e educação no portal de periódicos da CAPES: relatos de experiências docentes. Revista Exitus, Santarém/PA, Vol. 10, p. 01-28, 2020. Disponível em: http://dx.doi.org/10.24065/2237-9460.2020v10n0ID1255. Acesso em: 27 abr. 2020.

Recebido em: 20/01/2021.

Aprovado em: 04/06/2021. 